\title{
Third-line treatment for metastatic colorectal cancer: anlotinib is superior to chemotherapy and similar to fruquintinib or regorafenib
}

\author{
Y. CHENG ${ }^{1}$, F. C. DU², F. Q. FANG ${ }^{3}$, Z. J. DUAN ${ }^{4, *}$, W. LEI ${ }^{1}$, K. G. SHI ${ }^{1}$ \\ ${ }^{1}$ Dalian Medical University, Dalian, Liaoning, 116011, China; ${ }^{2}$ Department of Oncology, The Affiliated Yantai Yuhuangding Hospital of Qin- \\ gdao University, Qingdao University, Yantai, Shandong, 264000, China; ${ }^{3}$ Department of Oncology, First Affiliated Hospital of Dalian Medical \\ University, Dalian Medical University, Dalian, Liaoning, 116011, China; ${ }^{4}$ Department of Gastroenterology, First Affiliated Hospital of Dalian \\ Medical University, Dalian Medical University, Dalian, Liaoning, 116011, China
}

${ }^{*}$ Correspondence: 253682191@qq.com

Received November 25, 2019 / Accepted March 4, 2020

\begin{abstract}
The clinical efficiency and adverse reactions of anlotinib in metastatic colorectal cancer (mCRC) as a third-line treatment compared with chemotherapy and regorafenib or fruquintinib was explored in this study. Clinical data from $105 \mathrm{mCRC}$ patients who failed at least two lines of chemotherapy were collected. The patients were divided into three groups based on their third-line therapeutic regimen: third-line chemotherapy only (group A); anlotinib (group B); and fruquintinib or regorafenib (group C). The result showed that the ORR and DCR of group B (14.29\%, 85.71\%) were higher than those of group A $(0 \%, 40.00 \%)$. The ORRs of group B and group C were $14.29 \%$ and $20.00 \%$, respectively. Group B and group $\mathrm{C}$ had the same DCR, 85.71\%. The mean PFS values of group B (3.46 months) and group C (3.33 months) were longer than that of group A $(2.25$ months $)\left(\chi^{2}=84.255, \mathrm{p}<0.001\right)$ and the mean PFS values of group B and group C were similar $\left(\chi^{2}=0.884, \mathrm{p}=0.347\right)$. The mean OS of group B was 9.22 months, which was longer than that of group A (6.95 months) $\left(\chi^{2}=38.837, p<0.001\right)$. The mean OS values of group B (9.22 months) and group C (9.38 months) were not significantly different $\left(\chi^{2}=0.456, p=0.499\right)$. The incidences of proteinuria, hand-foot skin reaction, myelosuppression, and gastrointestinal reaction were similar between group $B$ and group $C(p=0.173,0.188,1.00,0.154$, respectively). Myelosuppression and gastrointestinal reaction were more common in group $\mathrm{A}$ than in group $\mathrm{B}$ and group $\mathrm{C}(\mathrm{p}<0.001)$. For $\mathrm{mCRC}$, anlotinib as a third-line treatment is better than chemotherapy and similar to regorafenib or fruquintinib. The associated adverse reactions are tolerable.
\end{abstract}

Key words: metastatic colorectal cancer, anlotinib, chemotherapy, fruquintinib; regorafenib

Colorectal cancer (CRC) is a common malignant tumor with the third highest mortality $[1,2]$. In China, the incidence of CRC is increasing, with an average annual rate of 4-5\%. In 2015, the number of new CRC cases and deaths caused by CRC doubled compared with the respective values 10 years ago, reaching 377,000 deaths and 191,100 cases, respectively $[3,4]$. For metastatic colorectal cancer (mCRC), chemotherapy is a traditional and classic method. Common chemotherapy regimens include CAPOX, FOLFOX4, and FOLFIRI. However, only $30-40 \%$ of patients can benefit from antitumor chemotherapy due to the low response rate. Although the clinical efficacy is improved when chemotherapy is combined with antiangiogenic drugs such as bevacizumab or cetuximab, the 5-year survival rate of advanced CRC is only $1-2 \%[5,6]$. Moreover, standard third-line treatment is absent. Therefore, it is of great significance to find effective third-line targeted drugs for mCRC patients.
Receptor tyrosine kinases (RTKs) are transmembrane glycoproteins that communicate with cellular growth factors and extracellular ligands. They are crucial for intracellular tyrosine phosphorylation and intracellular signaling. Many vital physiological processes, including cell proliferation, cell growth, cell migration, cell differentiation, and apoptosis, are mediated by RTK activation, which is regulated by protein tyrosine kinases (PTKs) and protein tyrosine phosphatases (PTPs) [7]. There is no or low activity and expression of most oncogenic RTKs in normal tissues, while hyperactive RTKs or upregulated oncogenic RTK levels in malignant cells have been confirmed by researchers $[8,9]$. Furthermore, in vitro, the downregulation of PTK activity can attenuate tumor cell growth, angiogenesis, and antiapoptotic effects [10].

Anlotinib is a newly approved orally administered smallmolecule RTK inhibitor. It targets RTKs related to tumor proliferation and metastasis, including vascular endothelial growth factor receptor (VEGFR), c-proto-oncogene 
protein, platelet-derived growth factor receptor (PDGFR), and fibroblast growth factor receptor (FGFR) [11, 12]. VEGF isoforms and VEGFRs are crucial proteins in vasculogenesis and angiogenesis. Studies have provided enough evidence to support their clinical effect as anticancer targets [13-15]. In vitro studies using recombinant enzymes showed that anlotinib selectively inhibited VEGFR2/KDR and VEGFR3 approximately 20 and 500 times as potently as sunitinib and sorafenib, respectively. On the other hand, the FGF/FGFR axis can result in aggressive cancer phenotypes by promoting cancer progression and enhancing the angiogenic potential of the tumor microenvironment [16, 17]. Moreover, FGF/FGFR signaling alterations are closely associated with chemotherapy resistance and poor clinical outcome [18-21]. Preclinical results indicated that anlotinib significantly inactivated FGFR1-4, especially FGFR2, to a greater extent than did sorafenib.

Clinical trials have proven the effective anticancer activity of anlotinib in advanced non-small-cell lung cancer (NSCLC) [22, 23], advanced soft tissue sarcoma (STS) [24, 25], advanced medullary thyroid cancer (MTC) [26, 27], and metastatic renal cell carcinoma (mRCC) [28]. However, the anticancer activity of anlotinib as a third-line treatment for mCRC requires more evidence. Further exploration is needed to determine whether the clinical effect of anlotinib as a third-line treatment for $\mathrm{mCRC}$ is superior to that of chemotherapy and other targeted therapies, such as regorafenib and fruquintinib. In this research, we compared the clinical effects of anlotinib, chemotherapy, and fruquintinib or regorafenib as third-line treatments for metastatic colorectal cancer.

In this article, a retrospective clinical analysis was conducted with data from the First Affiliated Hospital of Dalian Medical University from January 1, 2018, to January 1, 2020, to explore the clinical efficacy and safety of anlotinib compared with chemotherapy and fruquintinib or regorafenib for mCRC patients who failed at least two lines of chemotherapy.

\section{Patients and methods}

Patient selection. Eligible patients were those who presented with mCRC who failed at least two lines of chemotherapy, and they were admitted to the First Affiliated Hospital of Dalian Medical University and the Affiliated Yantai Yuhuangding Hospital of Qingdao University for third-line treatment from January 1, 2018, to January 1, $2020(n=105)$. Patients were without cardiac, liver, and renal dysfunctions, and other malignant tumors. The Eastern Cooperative Oncology Group (ECOG) scores of the selected patients ranged from 0 to 3 . The expected survival time was more than 3 months. In addition, those who had received traditional Chinese medicine in the past three months were not eligible.

Grouping. Patients were divided into three groups based on their third-line therapeutic regimen. Group A $(n=35)$ received third-line chemotherapy only. The chemotherapy regimen included irinotecan (from Hengrui Pharmacy Co. Ltd., Jiangsu. China; $300 \mathrm{mg} / \mathrm{m}^{2}$ intravenous drip for more than 90 minutes on the first day of a 21-day cycle) combined with raltitrexed (from Nanjing Zhengda Tianqing Pharmaceutical Co. Ltd., China; $2.6 \mathrm{mg} / \mathrm{m}^{2}$ intravenous drip for more than 15 minutes on the second day of a 21-day cycle) or raltitrexed only (Nanjing Zhengda Tianqing Pharmaceutical; $3 \mathrm{mg} / \mathrm{m}^{2}$ intravenous drip for more than 15 minutes on the first day of a 21-day cycle). The chemotherapy regimen was decided by three or more oncologists based on the previous chemotherapy patients had been given. Group B $(n=35)$ received anlotinib (Zhengda Tianqing Pharmaceutical; $12 \mathrm{mg} / \mathrm{d}$ per os from the first day to the fourteenth day of a 21-day cycle). Group $\mathrm{C}(\mathrm{n}=35)$ received fruquintinib (Hutchison Whampoa Pharmaceutical Co. Ltd., Shanghai, China; $5 \mathrm{mg} / \mathrm{d}$ per os from the first day to the twenty-first day of a 28-day cycle) or regorafenib (Bayer Pharmaceutical Co. Ltd., Germany; $160 \mathrm{mg} / \mathrm{d}$ per os from the first day to the twenty-first day of a 28-day cycle).

Follow-up and data collection. Follow-up ended as result of death or relapse or on January 1, 2020. The results of serum CEA, serum CA72-4, and serum CA19-9 values, as well as the results of contrast-enhanced computed tomography scans of the abdomen and chest, lymph node ultrasound, craniocerebral enhanced magnetic resonance imaging, emission computed tomography or positron emission tomographycomputed tomography were collected to carry out posttreatment assessments.

Efficacy and safety evaluation. Clinical efficacy was classified into complete remission (CR), partial remission $(\mathrm{PR})$, stable disease (SD), and progressive disease (PD) based on the Response Evaluation Criteria in Solid Tumors. The objective response rate (ORR) included the rates of CR and $\mathrm{PR}$. The disease control rate (DCR) included the rates of $\mathrm{CR}, \mathrm{PR}$, and SD. The overall survival (OS) duration was calculated as the interval from the day colorectal cancer was diagnosed to the end of follow-up or death. The progression-free survival (PFS) duration was calculated as the interval from the day treatment began to the end of followup or relapse. Adverse effects were evaluated as grade I-IV based on the Common Toxicity Criteria Version 3.0 of the National Cancer Institute.

Statistical analysis. Differences in qualitative data between the 3 groups were assessed by the chi-square test. Survival time was analyzed with the Kaplan-Meier method, and survival differences were analyzed by the log-rank test. Differences were regarded as meaningful when the p-value was less than 0.05. All data analysis was performed using the SPSS 21.0 software package (SPSS Inc., Chicago, IL, USA).

\section{Results}

Patient characteristics. The clinical characteristics of the cases in the three groups are provided in Table 1. These characteristics, including sex, age, ECOG score, metastasis, 
Table 1. Clinical characteristics of the patients.

\begin{tabular}{|c|c|c|c|c|c|}
\hline Groups & & Group A $(n=35)$ & Group B $(n=35)$ & Group C $(n=35)$ & p-value \\
\hline \multirow[t]{2}{*}{$\operatorname{Sex} \mathrm{n} / \%$} & Male & $16 / 45.71$ & $16 / 45.71$ & $18 / 51.43$ & 0.716 \\
\hline & Female & $19 / 54.29$ & $19 / 54.29$ & $17 / 48.57$ & \\
\hline \multirow[t]{2}{*}{ Age (y) n\% } & $\geq 60$ & $11 / 31.43$ & $13 / 37.14$ & $11 / 31.43$ & 0.581 \\
\hline & $<60$ & $24 / 68.57$ & $22 / 62.86$ & $24 / 68.57$ & \\
\hline \multirow[t]{4}{*}{ ECOG score n/\% } & 0 & 0 & 0 & 0 & 0.371 \\
\hline & 1 & $18 / 51.43$ & $19 / 54.29$ & $16 / 45.71$ & \\
\hline & 2 & $9 / 25.71$ & $9 / 25.71$ & $13 / 37.14$ & \\
\hline & 3 & $8 / 22.86$ & $7 / 20.00$ & $6 / 17.15$ & \\
\hline \multirow[t]{4}{*}{ Metastasis n/\% } & Pulmonary metastasis & $21 / 65.63$ & $26 / 74.29$ & $19 / 54.29$ & 0.091 \\
\hline & Bony metastasis & $14 / 40.00$ & $17 / 48.57$ & $15 / 42.86$ & 0.426 \\
\hline & Brain metastasis & $6 / 17.14$ & $7 / 20.00$ & $7 / 20.00$ & 0.823 \\
\hline & Hepatic metastasis & $29 / 82.86$ & $30 / 85.71$ & $29 / 82.86$ & 0.800 \\
\hline \multirow[t]{2}{*}{ Receipt of antiangiogenic drugs $\mathrm{n} / \%$} & Yes & $19 / 54.29$ & $21 / 60$ & $17 / 48.57$ & 0.294 \\
\hline & No & $16 / 45.71$ & $14 / 40$ & $18 / 51.43$ & \\
\hline \multirow[t]{2}{*}{ Receipt of radiotherapy $\mathrm{n} / \%$} & Yes & $16 / 45.71$ & $18 / 51.43$ & $20 / 57.14$ & 0.244 \\
\hline & No & $19 / 54.29$ & $17 / 48.57$ & $15 / 42.86$ & \\
\hline \multirow[t]{2}{*}{ Receipt of surgery n/\% } & Yes & $11 / 31.43$ & $13 / 37.14$ & $9 / 25.71$ & 0.297 \\
\hline & No & $24 / 68.57$ & $22 / 62.86$ & $26 / 74.29$ & \\
\hline \multirow[t]{2}{*}{ Receipt of TACE $\mathrm{n} / \%$} & Yes & $24 / 68.57$ & $25 / 71.43$ & $22 / 62.86$ & 0.453 \\
\hline & No & $11 / 31.43$ & $10 / 28.57$ & $13 / 37.14$ & \\
\hline
\end{tabular}

and receipt of antiangiogenic drugs (bevacizumab or cetuximab), TACE (transhepatic arterial chemoembolization), radiotherapy, or surgery, were not significantly different among the three groups ( $\mathrm{p}>0.05)$.

Clinical efficiency. The rates of CR, PR, SD, and PD in the three groups were significantly different $(p<0.001)$. All patients in the three groups did not achieve CR. The rates of PR and SD in group B (14.29\% and $71.42 \%$, respectively) were significantly higher than those in group A $(0 \%$ and $40.00 \%$, respectively). The rate of PD in group B (14.29\%) was less than that in group A $(60.00 \%)$. There was no significant difference in the rates of $\mathrm{PR}, \mathrm{SD}$, and $\mathrm{PD}$ between group B (14.29\%, $71.42 \%$, and $14.29 \%$, respectively) and group C $(20.00 \%, 65.71 \%$, and $24.29 \%$, respectively; $\mathrm{p}=0.539)$. The ORR and DCR in group B (14.29\% and $85.71 \%$, respectively) were higher than those in group A ( $0 \%$ and $40.00 \%$, respectively). The ORRs of group B and group C were $14.29 \%$ and $20.00 \%$, respectively. Group B and group C had the same DCR, $85.71 \%$. Data on clinical efficiency were detailed in Table 2.

Comparison of PFS and OS among the three groups. The mean PFS values of group B (3.46 months) and group C (3.33 months) were longer than that of group A (2.25 months) $\left(\chi^{2}=84.255, p<0.001\right)$ and the mean values of group $\mathrm{B}$ and group $\mathrm{C}$ were similar $\left(\chi^{2}=0.884, \mathrm{p}=0.347\right)$. The survival curves of the PFS for the three groups are shown in Figure 1. The survival curves of the PFS for group B and group $\mathrm{C}$ are detailed in Figure 2.
Table 2. Clinical efficacy of the three therapies.

\begin{tabular}{lcccc}
\hline Groups & $\begin{array}{c}\text { Group A } \\
(\mathbf{n = 3 5 )}\end{array}$ & $\begin{array}{c}\text { Group B } \\
(\mathbf{n}=\mathbf{3 5})\end{array}$ & $\begin{array}{c}\text { Group C } \\
(\mathbf{n}=\mathbf{3 5})\end{array}$ & p-value \\
\hline CR n/\% & 0 & 0 & 0 & \\
PR n/\% & 0 & $5 / 14.29$ & $7 / 20.00$ & $\mathrm{p}<0.001$ \\
$\mathrm{SD} \mathrm{n} / \%$ & $14 / 40.00$ & $25 / 71.42$ & $23 / 65.71$ & \\
PD n/\% & $21 / 60.00$ & $5 / 14.29$ & $5 / 14.29$ & \\
p-value & \multicolumn{4}{c}{$\mathrm{p}=0.539$} \\
\hline
\end{tabular}

The mean OS of group B was 9.22 months, longer than that of group A 6.95 months $\left(\chi^{2}=38.837, p<0.001\right)$. The mean OS values of group B (9.22 months) and group C (9.38 months) were not significantly different $\left(\chi^{2}=0.456, p=0.499\right)$. The survival curves of OS for the three groups are shown in Figure 3. Survival curves of OS for group B and group C are detailed in Figure 4.

Comparison of adverse effects. The incidences of adverse effects, including proteinuria, hand-foot skin reaction (HFSR), myelosuppression, and gastrointestinal reaction were similar between group B and group $C(p=0.173,0.188$, 1.00 , and 0.154 , respectively). It is worth noting that proteinuria and HFSR appeared in only group B and group C. Myelosuppression and gastrointestinal reaction were more common in group A than in group B and group C $(\mathrm{p}<0.001)$. The incidences of various adverse reactions in the three groups are detailed in Table 3. 


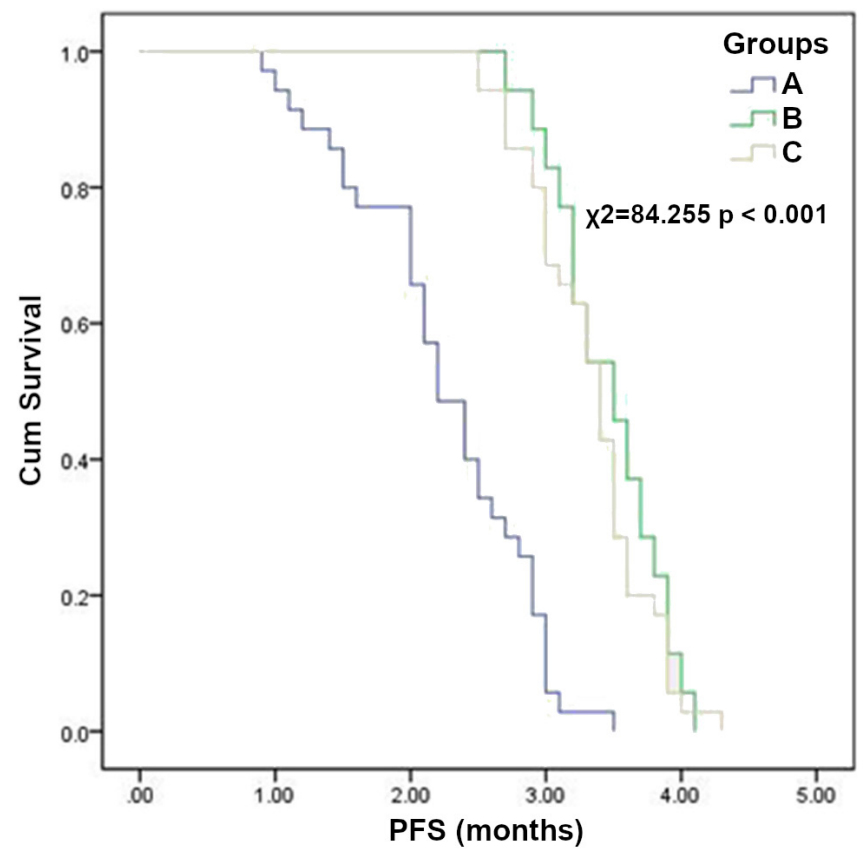

Figure 1. Survival curves of PFS for the three groups: group A) third-line chemotherapy only; group B) anlotinib; group C) fruquintinib or regorafenib. The mean PFS values of group $B$ (3.46 months) and group C (3.33 months) were longer than that of group $A(2.25$ months $)\left(\chi^{2}=84.255\right.$, $\mathbf{p}<0.001$ ).

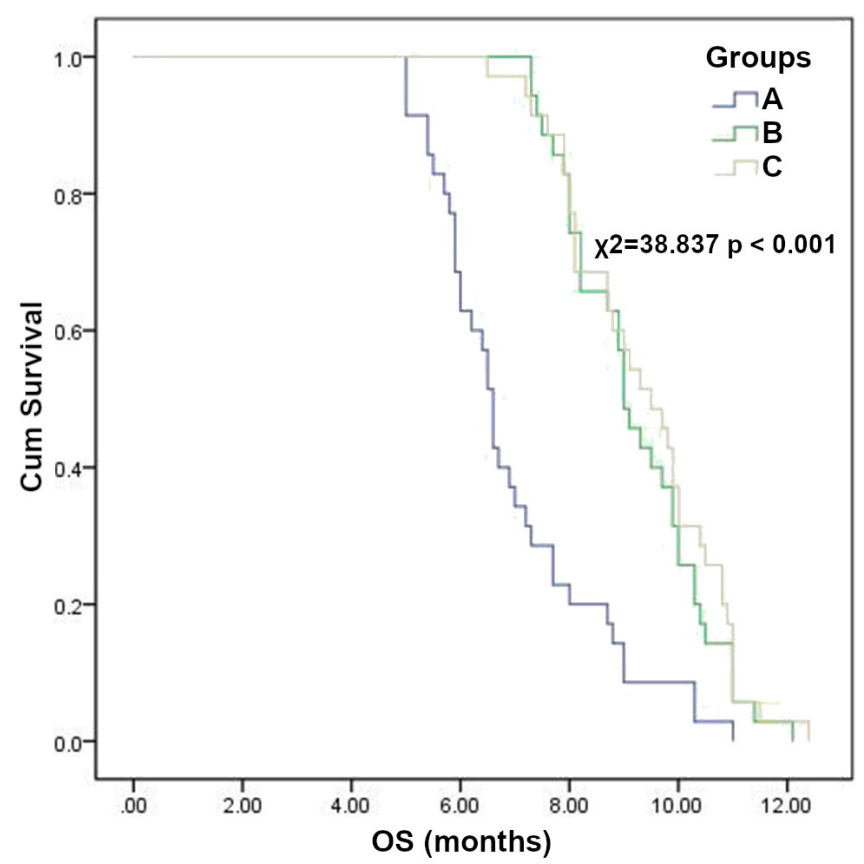

Figure 3. Survival curves of OS for the three groups: group A) third-line chemotherapy only; group B: anlotinib; group C: fruquintinib or regorafenib. The mean OS values of group $B(9.22$ months) and group $C(9.38$ months) were longer than that of group $A(6.95$ months $)\left(\chi^{2}=38.837\right.$, $\mathbf{p}<0.001)$.

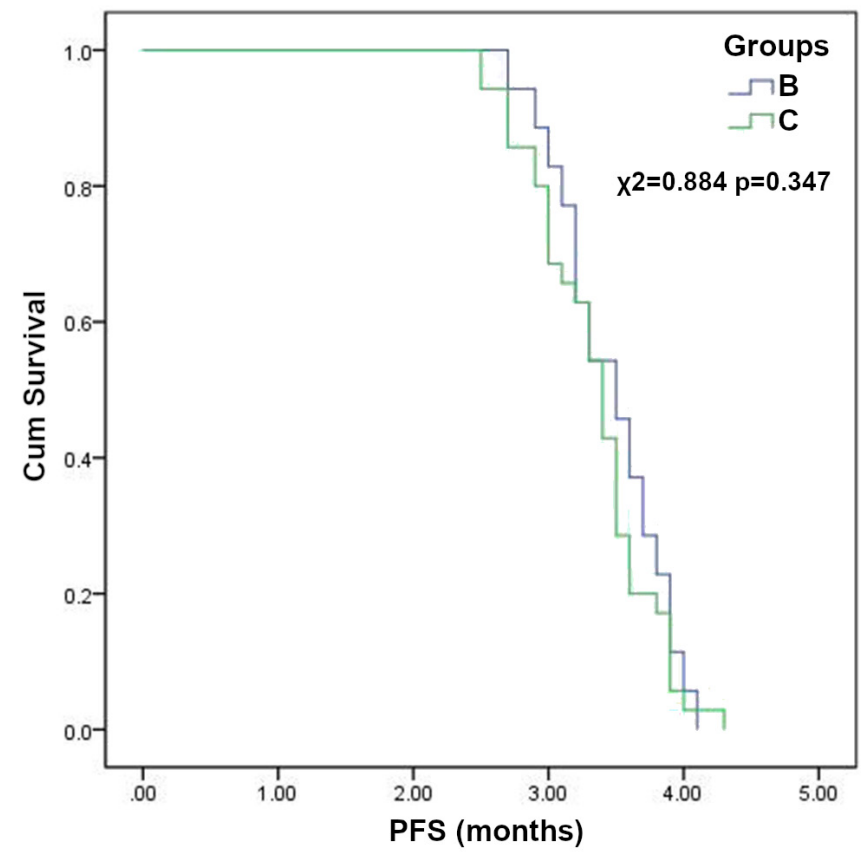

Figure 2. Survival curves of PFS for group B and group C: group B) anlotinib; group C) fruquintinib or regorafenib. The PFS values of group $B$ (3.46 months) and group C (3.33 months) were similar $\left(\chi^{2}=0.884\right.$, $\mathrm{p}=\mathbf{0 . 3 4 7 )}$.

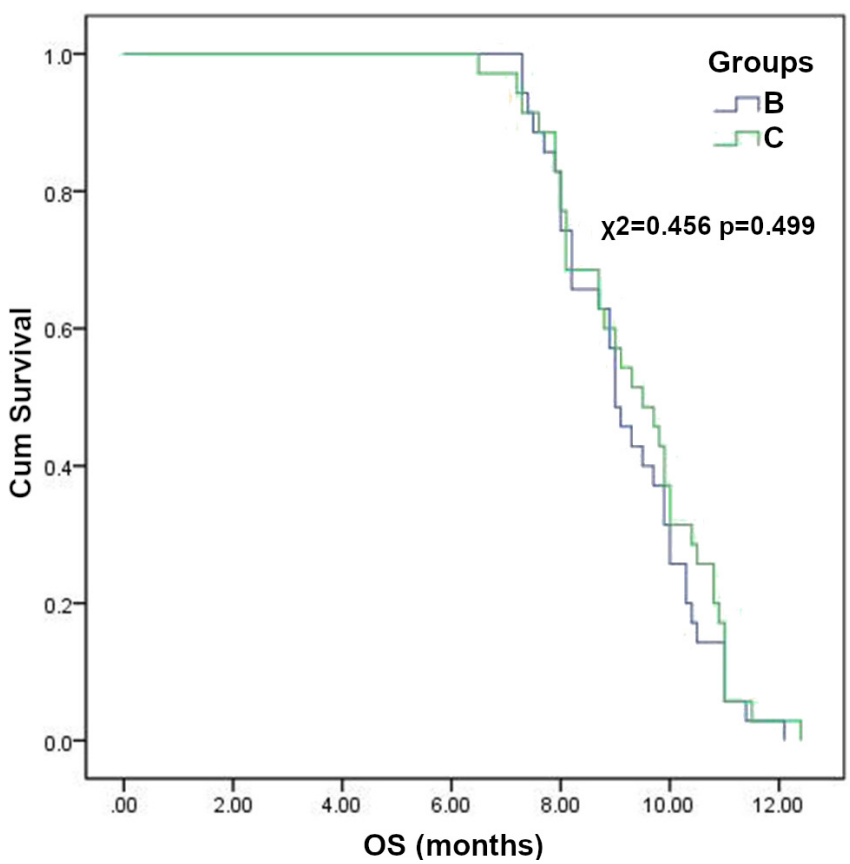

Figure 4. Survival curves of OS for group B and group C: group B) anlotinib; group $C$ ) fruquintinib or regorafenib. The mean $O S$ values of group $B$ (9.22 months) and group C (9.38 months) were not significantly different $\left(\chi^{2}=0.456, p=0.499\right)$. 
Table 3. Comparison of adverse effects among the three groups.

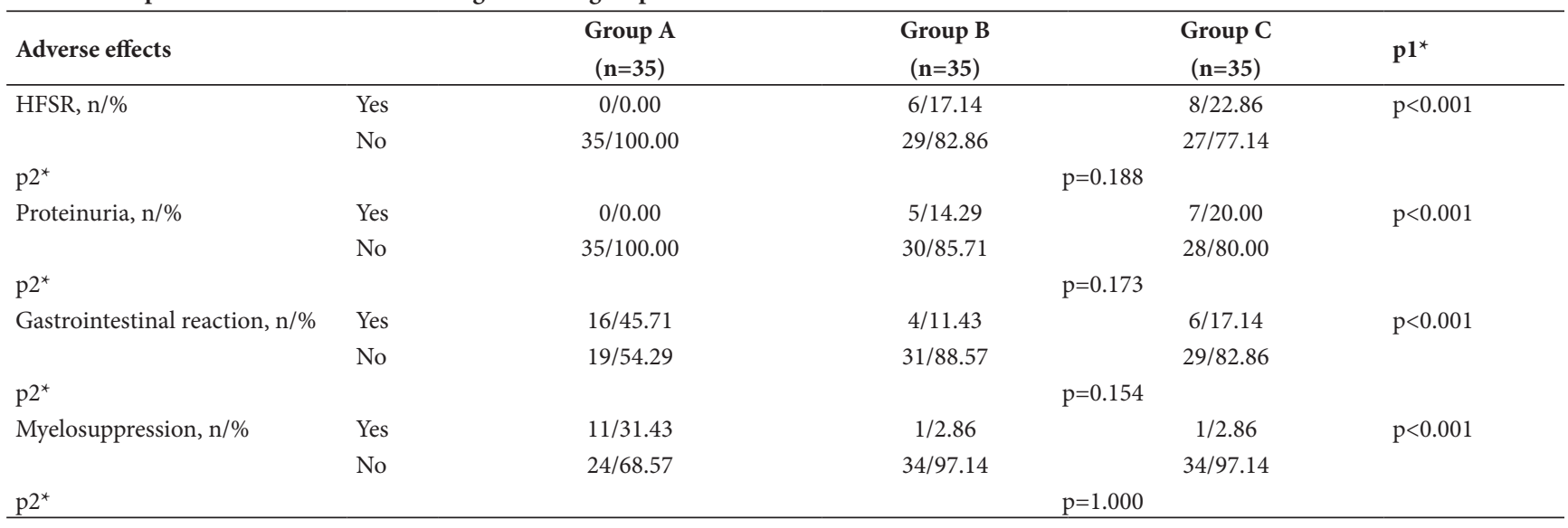

${ }^{*} \mathrm{p} 1$ : $\mathrm{p}$-value of the three groups; $\mathrm{p} 2$ : $\mathrm{p}$-value of group B vs. group C.

\section{Discussion}

Anlotinib can inhibit both tumor angiogenesis and tumor cell proliferation by targeting VEGFR1, VEGFR2/KDR, VEGFR3, c-Kit, PDGFR- $\alpha$, and fibroblast growth factor receptors (FGFR1, FGFR2, and FGFR3). Moreover, it can inhibit more targets than other RTK inhibitors, inc luding sorafenib, sunitinib, and pazopanib $[29,30]$. Therefore, it has recently become a hot topic of research.

Anlotinib has obtained good clinical results in advanced NSCLC [22, 23], advanced STS [24, 25], advanced MTC [26, 27], and mRCC [28]. A phase III trial named ALTER-0303 enrolled 437 advanced NSCLC patients who progressed after at least two lines of prior treatments. The ORR and DCR were improved in the anlotinib group compared with the placebo group (ORR 9.18\% vs. $0.7 \%, \mathrm{p}<0.0001$; DCR $80.95 \%$ vs. $37.06 \%, \mathrm{p}<0.0001)$. The median PFS and OS of the anlotinib group were prolonged compared with those of the placebo group (PFS 5.37 vs. 1.40 months, $\mathrm{p}<0.0001$; OS 9.63 vs. 6.30 months, $\mathrm{p}<0.0001$ ) [23]. Therefore, anlotinib was approved by the China Food and Drug Administration for third-line treatment or beyond in advanced NSCLC on May 8, 2018, in China [31]. Stacchiotti et al. conducted a phase IIB study that enrolled 233 advanced STS patients who were treatmentintolerant or progressed on anthracycline-based chemotherapy [25]. The results showed that the ORR and DCR in the anlotinib group were significantly higher than those in the control group (ORR $10.13 \%$ vs. $1.33 \%$, $\mathrm{p}=0.0145$; DCR $55.7 \%$ vs. $22.67 \%, \mathrm{p}<0.0001)$. The median PFS of anlotinib was significantly improved relative to that of the control (6.27 months vs. 1.47 months, $\mathrm{p}<0.0001$ ) [32]. The clinical study results were presented in the oral report section at the American Society of Clinical Oncology annual meeting. Zhou et al. conducted a multicenter randomized phase II trial that enrolled $133 \mathrm{mRCC}$ patients (93 treated with anlotinib and 40 treated with sunitinib) [27]. The results showed that the anlotinib and sunitinib groups had similar PFS values (11.3 vs. 11.0 months, $\mathrm{p}=0.30)$, ORR ( $24.4 \%$ vs. $23.3 \%)$ and 6 -week DCRs $(97.8 \%$ vs. $93.0 \%, \mathrm{p}=0.33$ ) [27]. A phase II trial enrolled 58 patients with advanced or relapsed MTC who could not receive radical surgery and treated them with anlotinib. The average PFS was 12.8 months (median PFS not reached), the overall ORR was $48.28 \%$, and the DCRs at weeks 24 and 48 were $92.16 \%$ and $84.53 \%$, respectively [28].

However, there has been no clinical study exploring the efficiency and safety of anlotinib as a treatment for mCRC. There are limited methods for treating mCRC, especially for patients who progress after at least two lines of prior treatments. Therefore, it is of great significance to find effective third-line targeted drugs for mCRC patients. In this retrospective clinical analysis, one hundred and five mCRC patients who failed at least two lines of chemotherapy were divided into three groups based on their third-line therapeutic regimen. Their basic clinical characteristics were very similar. After follow-up and analysis, none of the patients in the three groups achieved a CR. The PR and SD rates of group B (14.29\% and $71.42 \%$, respectively) were significantly higher than those of group A ( $0 \%$ and $40.00 \%$, respectively). The rate of PD in group B (14.29\%) was less than that in group A (60.00\%). There was no significant difference in the rates of PR, SD, or PD between group B (14.29\%, 71.42\%, and $14.29 \%$, respectively) and group C $(20.00 \%, 65.71 \%$, and $24.29 \%$, respectively) $(\mathrm{p}=0.539)$. The ORR and DCR of group B ( $14.29 \%$ and $85.71 \%$, respectively) were higher than those of group A ( $0 \%$ and $40.00 \%$, respectively). The ORRs of group B and group C were $14.29 \%$ and $20.00 \%$, respectively. Group B and group C had the same DCR, 85.71\%. The mean PFS values of group B (3.46 months) and group C (3.33 months) were longer than that of group A (2.25 months) $\left(\chi^{2}=84.255, \mathrm{p}<0.001\right)$ and the mean PFS values of group $\mathrm{B}$ and group $\mathrm{C}$ were similar $\left(\chi^{2}=0.884, \mathrm{p}=0.347\right)$. The mean OS of group B was 9.22 months, longer than that of group A (6.95 months) $\left(\chi^{2}=38.837, \mathrm{p}<0.001\right)$. The mean OS values of group B (9.22 months) and group C (9.38 months) 
were not significantly different $\left(\chi^{2}=0.456, p=0.499\right)$. The incidences of adverse effects, including proteinuria, handfoot skin reaction (HFSR), myelosuppression, and gastrointestinal reaction were similar between group $\mathrm{B}$ and group $\mathrm{C}(\mathrm{p}=0.173,0.188,1.00$, and 0.154 , respectively). It is worth noting that proteinuria and HFSR appeared in only group B and group C. Myelosuppression and gastrointestinal reaction were more common in group A than in group B and group $\mathrm{C}(\mathrm{p}<0.001)$.

The reason why anlotinib can obtain good clinical efficiency in various cancers, including $\mathrm{mCRC}$, may be closely related to its molecular mechanism. Preclinical studies on endothelial cells provided enough evidence to prove that cell migration and the formation of capillary-like tubes induced by EGF/PDGF-BB/FGF-2 can be inhibited by anlotinib. The possible mechanisms may be that anlotinib inhibits the activation of VEGFR2, PDGFR $\beta$, and FGFR1, as well as downstream ERK signaling. In addition, anlotinib can bind to the ATP-binding pocket of the VEGFR2 tyrosine kinase and inhibit VEGFR2 with high selectivity (IC50 $<1 \mathrm{nM}$ ), thereby inhibiting VEGF-stimulated proliferation of human umbilical vein endothelial cells (HUVECs). Moreover, HUVEC migration, tube formation, and microvessel growth in vitro were suppressed and vascular density was reduced in vivo by anlotinib [33]. In summary, anlotinib obtained good clinical efficiency in various cancers by effectively inhibiting cell proliferation and migration signaling pathways via multiple targets.

In this retrospective clinical analysis, anlotinib had an outstanding clinical effect in the treatment of mCRC patients who progressed after at least two lines of prior treatments in terms of the ORR, DCR, and survival time. This means that anlotinib may become another effective targeted drug for mCRC. Of course, these results need to be supported by clinical trials with larger sample sizes.

In conclusion, anlotinib, as a newly approved orally administrative small-molecule RTK inhibitor, has better clinical efficiency as a third-line treatment than chemotherapy for metastatic colorectal cancer patients who failed at least two lines of chemotherapy. In comparison to that of other targeted drugs, such as regorafenib or fruquintinib, the clinical effect is comparable, and the adverse reactions are similar and tolerable.

Acknowledgments: This work was supported by the National Natural Science Foundation of China (81670479).

\section{References}

[1] XU J, KIM TW, SHEN L, SRIURANPONG V, PAN H et al. Results of a randomized, double-blind, placebo-controlled, phase III Trial of Trifluridine/ Tipiracil (TAS-102) monotherapy in Asian patients with previously treated metastatic colorectal cancer: the TERRA Study. J Clin Oncol 2018; 36: 350-358. https://doi.org/10.1200/JCO.2017.74.3245
[2] SEPULVEDA AR, HAMILTON SR, ALLEGRA CJ, GRODY CJ, GRODY W et al. Molecular biomarkers for the evaluation of colorectal cancer: guideline from the American Society for Clinical Pathology, College of American Pathologists, Association for Molecular Pathology, and the American Society of Clinical Oncology. J Clin Oncol 2017; 35: 1453-1486. https://doi.org/10.1200/JCO.2016.71.9807

[3] CHEN W, ZHENG R, BAADE PD, ZHANG S, ZENG H et al. Cancer statistics in China, 2015. CA Cancer J Clin 2016; 66: 115-132. https://doi.org/10.3322/caac.21338

[4] VARDY JL, DHILLON HM, POND GR, ROURKE SB, BEKELE $T$ et al. Cognitive function in patients with colorectal cancer who do and do not receive chemotherapy: a prospective, longitudinal, controlled study. J Clin Oncol 2015; 33: 4085-4092. https://doi.org/10.1200/JCO.2015.63.0905

[5] MODEST DP, STINTZING S,VON WEIKERSTHAL LF, DECKER T, KIANI A et al. Impact of subsequent therapies on outcome of the FIRE-3/AIO KRK0306 trial: first-line therapy with FOLFIRI plus cetuximab or bevacizumab in patients with KRAS wild-type tumors in metastatic colorectal cancer. J Clin Oncol 2015; 33: 3718-3726. https://doi. org/10.1200/JCO.2015.61.2887

[6] CASADEI GARDINI A, SCARPI E, ORLANDI E, TASSINIARI D, LEO $S$ et al. Prognostic role of aspartate aminotransferase-lymphocyte ratio index in patients with metastatic colorectal cancer: results from the randomized ITACa trial. Onco Targets Ther 2018;11: 5261-5268. https://doi. org/10.2147/OTT.S166614

[7] PERSSON C, SJOBLOM T, GROED A, KAPPERT K, ENGSTROM U et al. Preferential oxidation of the second phosphatase domain of receptor-like PTP- $\alpha$ revealed by an antibody against oxidized protein tyrosine phosphatases. Proc Natl Acad Sci U S A 2004; 101: 1886-91. https://doi. org/10.1073/pnas.0304403101

[8] HOJJAT-FARSANGI M. Small-molecule inhibitors of the receptor tyrosine kinases: promising tools for targeted cancer therapies. Int J Mol Sci 2014; 15: 13768-13801. https:// doi.org/10.3390/ijms150813768

[9] HUBBARD SR, MILLER WT. Receptor tyrosine kinases: mechanisms of activation and signaling. Curr Opin Cell Biol 2007; 19: 117-123. https://doi.org/10.1016/j.ceb.2007.02.010

[10] ARORA A, SCHOLAR EM. Role of tyrosine kinase inhibitors in cancer therapy. J Pharmacol Exp Ther 2005; 315: 971979. https://doi.org/10.1124/jpet.105.084145

[11] SHEN G, ZHENG F, REN D, DU F, DONG Q. Anlotinib: a novel multi-targeting tyrosine kinase inhibitor in clinical development. J Hematol Oncol 2018; 11: 120. https://doi. org/10.1186/s13045-018-0664-7

[12] HAN B, LI K, WANG Q, ZHANG L, SHI J et al. Effect of Anlotinib as a third-line or further treatment on overall survival of patients with advanced non-small cell lung cancer: the ALTER 0303 phase 3 randomized clinical trial. JAMA Oncol 2018; 4: 1569-1575. https://doi.org/10.1001/jamaoncol.2018.3039

[13] STRUMBERG D, RICHLY H, HILGER H, SCHLEUCHER $\mathrm{N}$, KORFEE $\mathrm{S}$ et al. Phase I clinical and pharmacokinetic study of the Novel Raf kinase and vascular endothelial growth factor receptor inhibitor BAY 43-9006 in patients with advanced refractory solid tumors. J Clin Oncol 2005; 23: 965-972. https://doi.org/10.1200/JCO.2005.06.124 
[14] MROSS K, FROST A, STEINBILD S, HEDBOM S, BUCHERT $\mathrm{M}$ et al. A phase I dose-escalation study of regorafenib (BAY 73-4506), an inhibitor of oncogenic, angiogenic, and stromal kinases, in patients with advanced solid tumors. Clin Cancer Res 2012; 18: 2658-2667. https://doi. org/10.1158/1078-0432.CCR-11-1900

[15] HUANG L, HUANG Z, BAI Z, XIE R, SUN L et al. Development and strategies of VEGFR-2/KDR inhibitors. Future Med Chem 2012; 4: 1839-1852. https://doi.org/10.4155/ fmc. 12.121

[16] KNIGHTS V, COOK SJ. De-regulated FGF receptors as therapeutic targets in cancer. Pharmacol Ther 2010; 125: 105-117. https://doi.org/10.1016/j.pharmthera.2009.10.001

[17] WESCHE J, HAGLUND K, HAUGSTEM EM. Fibroblast growth factors and their receptors in cancer. Biochem J 2011; 437: 199-213. https://doi.org/10.1042/BJ20101603

[18] TURNER N, PEARSON A, SHARPE R, LAMBROS M, GEYER F et al. FGFR1 amplification drives endocrine therapy resistance and is a therapeutic target in breast cancer. Cancer Res 2010; 70: 2085-2094. https://doi.org/10.1158/0008-5472. CAN-09-3746

[19] ELBAUOMY ELSHEIKH S, GREEN AR, LAMBROS MB, TURNER NC, GRAINGE MJ et al. FGFR1 amplification in breast carcinomas: a chromogenic in situ hybridisation analysis. Breast Cancer Res 2007; 9: R23. https://doi.org/10.1186/ bcr 1665

[20] MATSUMOTO K, ARAO T, HAMAGUCHI T, HAMAGUCHI T, SHIMADA Y et al. FGFR2 gene amplification and clinicopathological features in gastric cancer. Br J Cancer 2012; 106: 727-732. https://doi.org/10.1038/bjc.2011.603

[21] DENG N, GOH LK, WANG H, DAS K, TAO J et al. A comprehensive survey of genomic alterations in gastric cancer reveals systematic patterns of molecular exclusivity and cooccurrence among distinct therapeutic targets. Gut 2012; 61: 673-684. https://doi.org/10.1136/gutjnl-2011-301839

[22] HAN B, LI K, ZHAO, LI B, CHENG Y et al. Anlotinib as a third-line therapy in patients with refractory advanced nonsmall-cell lung cancer: a multicentre, randomised phase II trial (ALTER0302). Br J Cancer 2018; 118: 654-661. https:// doi.org/10.1038/bjc.2017.478

[23] HAN B, LI K, WANG Q, ZHAO Y, ZHANG L et al. Third-line treatment: a randomized, double-blind, placebo-controlled phase III ALTER-0303 study-efficacy and safety of anlotinib treatment in patients with refractory advanced NSCLC. J Clin Oncol 2013; 35: 9053-9053. https://doi.org/10.1200/ JCO.2017.35.15_suppl.9053
[24] CHI Y, SUN Y, CAI J, YAO Y, HONG X et al. Phase II study of anlotinib for treatment of advanced soft tissues sarcomas. J Clin Oncol 2016; 34: 11005. https://doi.org/10.1200/ JCO.2016.34.15_suppl.11005

[25] STACCHIOTTI S, NEGRI T, ZAFFARONI N, PALASSINI E, MOROSI C et al. Sunitinib in advanced alveolar soft part sarcoma: evidence of a direct antitumor effect. Ann Oncol 2011; 22: 1682-1690. https://doi.org/10.1093/annonc/mdq644

[26] ZHOU AP, BAI Y, SONG Y, LI H, XIE X et al. Anlotinib in metastatic renal cell carcinoma (mRCC) with a previous anti-VEGFR TKI: preliminary results from a multicenter, phase II trial. J Clin Oncol 2016; 34: e16082. https://doi. org/10.1200/JCO.2016.34.15_suppl.e16082

[27] ZHOU AP, MA J, BAI Y, SONG Y, LI H et al. Anlotinib versus sunitinib as first line treatment for metastatic renal cell carcinoma (mRCC): preliminary results from a randomized phase II clinical trial. J Clin Oncol 2016; 34: 4565. https://doi. org/10.1200/JCO.2016.34.15_suppl.4565

[28] SUN Y, CHI Y, TANG P, GAO M, JI Q et al. Phase II study of anlotinib for treatment of advanced medullary thyroid carcinoma. J Clin Oncol 2016; 34: 6015. https://doi.org/10.1200/ JCO.2016.34.15_suppl.6015

[29] XIE C, WAN X, QUAN H, ZHENG M, FU L et al. Preclinical characterization of anlotinib, a highly potent and selective vascular endothelial growth factor receptor-2 inhibitor. Cancer Sci 2018; 109: 1207-1219. https://doi.org/10.1111/ cas. 13536

[30] TAURIN S, YANG CH, REYES M, CHO S, JARBOE EA et al. Abstract 3244: treatment of endometrial cancer cells with a new small tyrosine kinase inhibitor targeting mutated fibroblast growth factor receptor-2. Cancer Res 2017; 77: 3244. https://doi.org/10.1158/1538-7445.AM2017-3244

[31] China Food and Drug Administration, Approved drugs, Anlotinib [internet]. Accessed 8 May 2018. http://app1.sfda.gov. $\mathrm{cn} /$ datasearch $/$ face $/$ base.jsp?tableId $=25 \&$ tableName $=$ TAB LE25\&title=\%E5\%9B\%BD\%E4\%BA\%A7\%E8\%8D\%AF\%E5 $\% 93 \% 81 \& b c I d=124356560303886909015737447882$.

[32] CHI Y, YAO Y, WANG S, HUANG G, CAI Q et al. Anlotinib for metastasis soft tissue sarcoma: a randomized, double-blind, placebocontrolled and multi - centered clinical trial. J Clin Oncol 2018; 36: 11503. https://doi.org/10.1200/ JCO.2018.36.15_suppl.11503

[33] TAURIN S, YANG CH, REYES M, CHO S, COOMBS DM et al. Endometrial cancers harboring mutated fibroblast growth factor receptor 2protein are successfully treated with a new small tyrosine kinase inhibitor in an orthotopic mouse model. Int J Gynecol Cancer 2018; 28: 152-160. https://doi. org/10.1097/IGC.0000000000001129 